\title{
THE MODIFIED MOHR - COULOMB AND DRUCKER - PRAGER MODELS. INFLUENCE OF ECCENTRICITY ON HYSTERESIS LOOP AND ENERGY LOSS
}

\author{
Alexander V. Dudchenko ${ }^{1,2}$, Sergey V. Kuznetsov ${ }^{1,3}$ \\ ${ }^{1}$ National Research Moscow State University of Civil Engineering, Moscow, RUSSIA \\ ${ }^{2}$ LLC "Podzemproekt”, Moscow, RUSSIA \\ ${ }^{3}$ Institute for Problems in Mechanics, Russian Academy of Sciences, Moscow, RUSSIA
}

\begin{abstract}
Annotation: The eccentricity parameters appearing in the modified Mohr-Coulomb and Drucker-Prager models are studied. The influence of the eccentricity on shape and size of the hysteretic loop and plastic dissipation energy are analyzed. Both kinematic and force loadings are considered.
\end{abstract}

Keywords: Mohr-Coulomb, Drucker-Prager, eccentricity, hysteresis, plastic dissipation energy

\section{МОДИФИЦИРОВАННЫЕ МОДЕЛИ МОРА - КУЛОНА И ДРАКЕРА - ПРАГЕРА. ВЛИЯНИЕ ЭКСЦЕНТРИСИТЕТОВ НА ГИСТЕРЕЗИСНЫЕ ПЕТЛИ И ДИССИПАЦИЮ ЭНЕРГИИ}

\author{
А.В. Дудченко ${ }^{1,2}$, С.В. Кузнецов ${ }^{1,3}$ \\ ${ }^{1}$ Национальный исследовательский Московский государственный строительный университет, \\ г. Москва, РОССИЯ \\ ${ }^{2} \mathrm{OOO}$ «Подземпроект», г. Москва, РОССИЯ \\ ${ }^{3}$ Институт проблем механики Российской академии наук, г. Москва, РОССИЯ
}

\begin{abstract}
АННОТАЦИЯ: Изучены параметры эксцентриситета, появляющиеся в модифицированных моделях Мора - Кулона и Дракера - Прагера. Проанализировано влияние эксцентриситетов на форму и размер гистерезисной петли, и диссипацию энергии при работе модели в пластическом состоянии.
\end{abstract}

Ключевые слова: Мор - Кулон, Дракер - Прагер, эксцентриситет, гистерезис, пластическая диссипация энергии

\section{INTRODUCTION}

The analyzed modified Mohr-Coulomb [1] and modified Drucker-Prager [2] models differ from the original plasticity models [3] by introducing the eccentricity parameters allowing to avoid the loss of smoothness at the apex points of the corresponding yield surfaces (meridional eccentricity), and, for a Mohr-Coulomb model, to eliminate losses of smoothness at the pyramid edges (deviatoric eccentricity). Thus, the modified Mohr-Coulomb model is characterized by the two eccentricity parameters: meridional and deviatoric eccentricities, while the modified
Drucker-Prager is characterized by the deviatoric eccentricity only.

Both the original Mohr-Coulomb and DruckerPrager models can be characterized by the following equation

$$
\begin{aligned}
& f\left(p, q_{\sigma},\left\|\boldsymbol{\varepsilon}_{p l}\right\|\right) \equiv R(\Theta, \varphi) q_{\sigma}- \\
& -c\left(\left\|\boldsymbol{\varepsilon}_{p l}\right\|\right)-p \tan \varphi=0
\end{aligned}
$$

where $c$ is the cohesion, possibly depending on the plastic strain measure $\left\|\boldsymbol{\varepsilon}_{p l}\right\|$ in a case of 
plastic hardening; $\varphi$ is the angle of internal friction; the pressure $p$ is defined by

$$
p=-\frac{1}{3} \operatorname{tr}(\sigma)
$$

the deviatoric stress measure takes the form

$$
q_{\sigma}=\left\{\begin{array}{l}
\underbrace{\frac{1}{2}\left(\sigma_{\max }-\sigma_{\min }\right)}_{\text {Mohr-Coulomb }} \\
\underbrace{\sqrt{\frac{3}{2}} \sqrt{I I_{\sigma}-3 p^{2}}}_{\text {Drucker-Prager }}
\end{array}\right.
$$

in (1.3) $\sigma_{\max }, \sigma_{\min }$ are maximum and minimum principle stresses, respectively, and

$$
I I_{\sigma}=\sigma \cdot \sigma
$$

$R(\Theta, \varphi)$ is the dimensionless parameter depending on $\varphi$ and the angle $\Theta$ between the meridional plane and the axis of one of the principle stresses, the pressure. In the MohrCoulomb model the coefficient $R(\Theta, \varphi)$ takes the form

$$
\begin{aligned}
& R(\Theta, \varphi)=\frac{\sin \left(\Theta+\frac{\pi}{3}\right)}{\sqrt{3} \cos \varphi}+ \\
& +\frac{1}{3} \cos \left(\Theta+\frac{\pi}{3}\right) \tan \varphi
\end{aligned}
$$

Similar formula for the coefficient $R(\Theta, \varphi)$ can be introduced for the Drucker-Prager model.

1.1. Deviatoric eccentricity. The deviatoric eccentricity is introduced by the following equation that modifies the original MohrCoulomb model:

$$
\begin{aligned}
& R_{e}(\Theta, \varphi)= \\
& \left.=\frac{\left[4\left(1-e^{2}\right) \cos ^{2} \Theta+(2 e-1)^{2}\right](3-\sin \varphi)}{6 \cos \varphi\left[2\left(1-e^{2}\right) \cos \Theta+(2 e-1) \sqrt{4\left(1-e^{2}\right) \cos ^{2} \Theta+5 e^{2}-4 e}\right.}\right]
\end{aligned}
$$

The smoothing parameter $e$ varies in the interval $\frac{1}{2}<e \leq 1$, and while at $e=1$ the coefficient $R_{1}(\Theta, \varphi)$ becomes independent upon $\Theta$

$$
R_{1}(\Theta, \varphi)=\frac{3-\sin \varphi}{6 \cos \varphi+1}
$$

at $e \rightarrow \frac{1}{2}$ the smoothed curve tends to Rankine's triangle corresponding to the friction angle $\varphi=90^{\circ}$.

1.2. Meridional eccentricity. In the meridional plane both the Mohr-Coulomb and the DruckerPrager model admit the following smoothness that can be characterized by the hyperbolic potential

$$
\begin{aligned}
& g\left(p, q_{\sigma},\left\|\boldsymbol{\varepsilon}_{p l}\right\|\right) \equiv \\
& \equiv \sqrt{\left(R_{e}(\Theta, \varphi) q_{\sigma}\right)^{2}+(\varepsilon c(0) \tan \varphi)^{2}}-p \tan \varphi=0
\end{aligned}
$$

where $\varepsilon$ is the smoothing parameter varied in the interval $0<\varepsilon<1$. At $\varepsilon \rightarrow 0$ the hyperbolic approximation tends to the initial curve (1.1), (for a modified Mohr-Coulomb model the coefficient $R(\Theta, \varphi)$ should be replaced by the smoothed coefficient $\left.R_{e}(\Theta, \varphi)\right)$. At $\varepsilon \rightarrow 1$ the smoothed curve in the meridional plane becomes a hyperbola with locus at $p=c(0)$.

\section{FE SIMULATIONS}

Herein, some results based on numerical simulation of behavior of elastoplastic media are 
The Modified Mohr - Coulomb and Drucker - Prager Models. Influence of Eccentricity on Hysteresis Loop and Energy Loss

presented. The given results were carried out by FE code using Drucker-Pruger and MohrCoulomb models of plasticity (yield criteria).

2.1 Finite element model. The model is a cube with the size of one finite element. The displacements along the $\mathrm{x}$ axis on the face of the cube which is parallel to $\mathrm{YOZ}$ are fixed, while on the opposite face cyclic loading is applied, Figure 1. This loading can be given as a kinematic or force factor with the frequency $v$. Other faces of the model are free. In addition, volumetric kinematic loading will be also considered. In that case, the displacements along the $\mathrm{Z}, \mathrm{X}$ and $\mathrm{Y}$ axis are fixed on the three faces which are parallel to XOY, YOZ and XOZ respectively. On the opposite faces cyclic kinematic loading are applied.

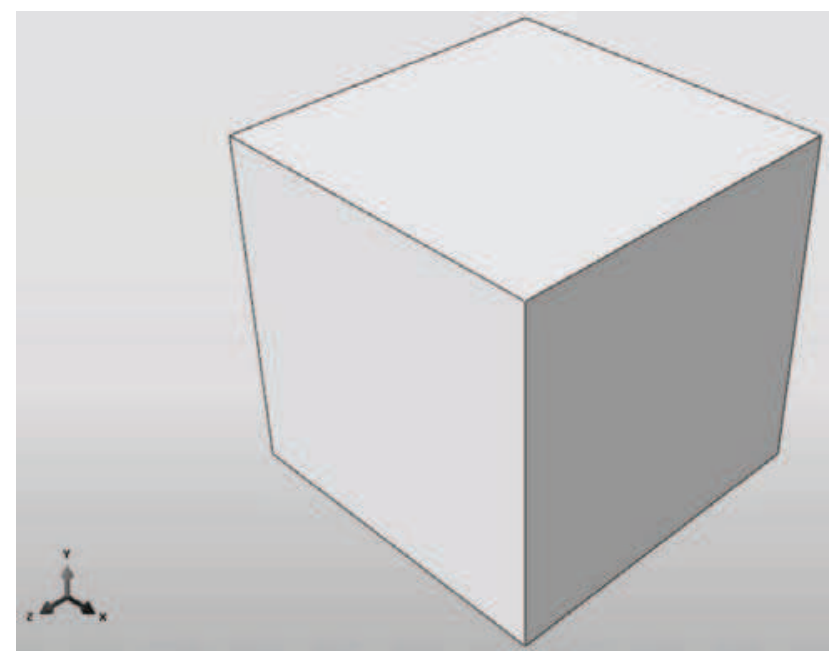

Figure 1. Finite element model.

Comparing the energy dissipated by plastic deformation (2.1) as well as strain-stress curves gives the information on the influence of variables included in the mathematical models of plastic media (damping factor and eccentricities).

$$
A^{p}=\int \sigma_{i j} d \varepsilon_{i j}^{p}
$$

2.2 The influence of damping factor. Damping factor is used for automatic stabilization of static problems during the non-linear quasi- static solution procedure. Viscous forces are added to the global equilibrium equations in the form:

$$
F=d M \mathbf{v},
$$

where $d$ is the damping factor, $\mathrm{M}$ is the mass matrix,

$$
\mathrm{v}=\Delta \mathbf{u} / \Delta t
$$

is vector of nodal velocities (in the context of this problem it does not have a physical meaning). This value is used to ensure the convergence of the solution. Nevertheless, there is no guarantee that the value of damping will be suitable for the problem. Therefore, it is important to estimate whether the quantity is appropriate for the convergence of the solution.

a. Hardening plasticity. The hardening, as a result of the influence of symmetric and asymmetric cyclic loading, was simulated using Mohr-Coulomb plasticity model.

Variation of the character of stress-strain curves, due to variation of the damping factor at other fixed parameters in the model, subjected to cyclic loading is presented in Figures 2 and 3.

The charts in figures 2 and 3 are plotted at $\varphi=\psi=0, \quad \operatorname{decc}=1, \quad m e c c=0.1$ and $c=0.001$, where $\varphi$ (phi) is the angle of internal friction, $\psi$ (psi) is the dilation angle, $\mathrm{c}$ is cohesion, decc and mecc are deviatoric and meridional eccentricities respectively.

As can be seen from the charts above, even large values of the damping factor can ensure the convergence of the solution procedure. However, the large values are not suitable because a further decline in the damping factor affects the solution significantly. Thus, the maximum value for damping is $1 \mathrm{e}-6$, as further decreases do not cause any substantial changes.

Similar results were obtained for asymmetric loading (Figures 4 and 5). The charts in Figures 4 and 5 are plotted at $\varphi=\psi=0, c=0.001$, decc $=1$ and $m e c c=1$. 
Thus, to be suitable for the problem, the value of the damping factor should not affect the character of stress-strain curves when it decreases.
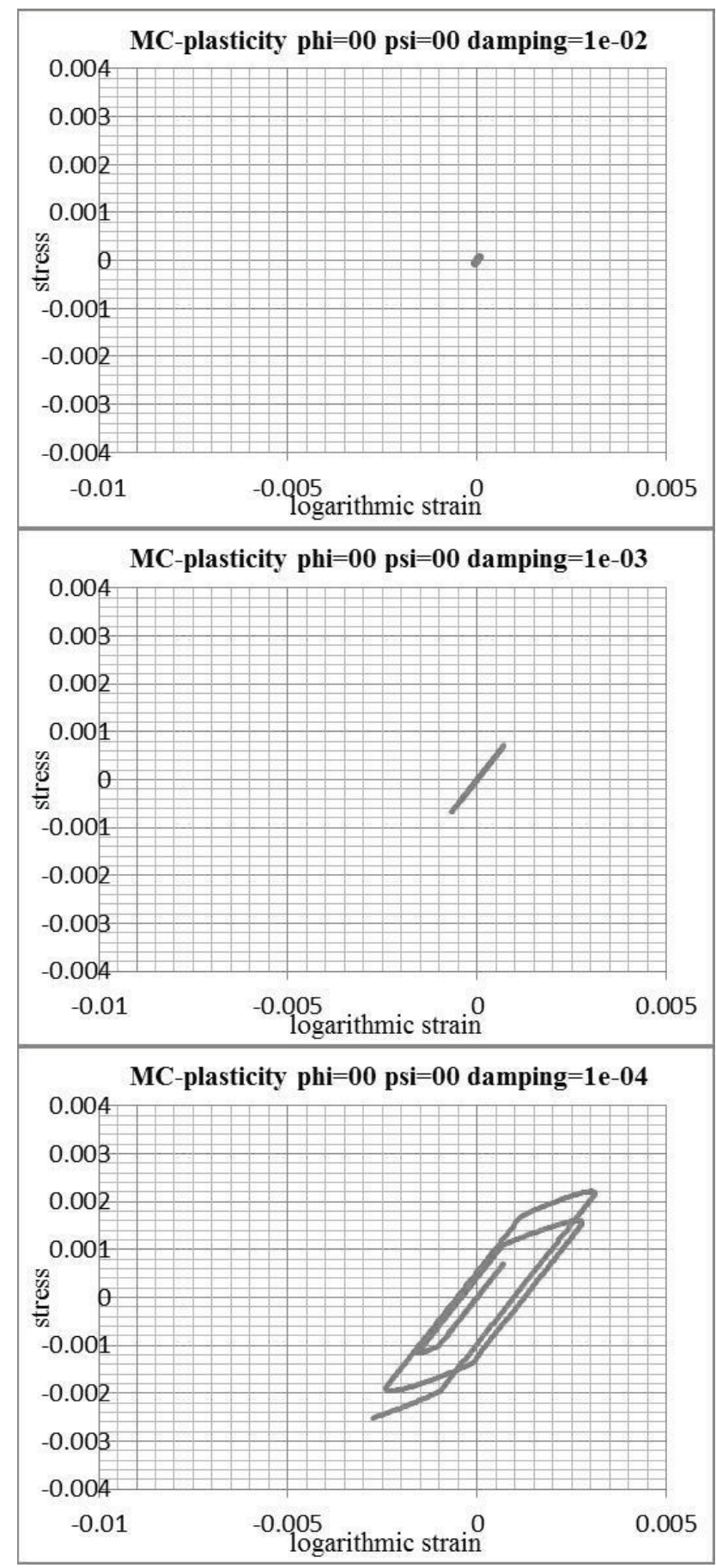

Figure 2. Stress-strain curves for symmetric cycle loading at different values of damping.
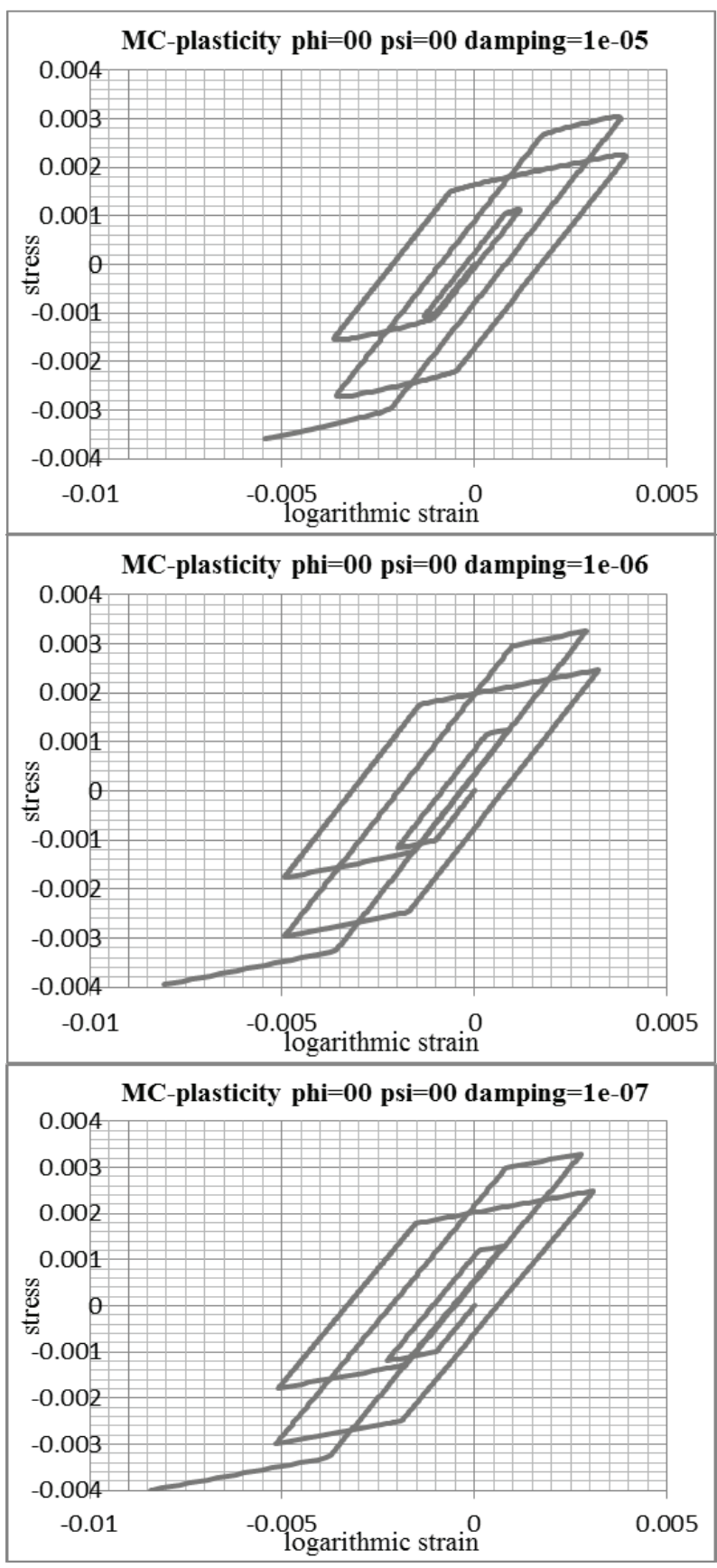

Figure 3. Stress-strain curves for symmetric cycle loading at different values of damping.

As can be seen from the charts above, even large values of the damping factor can ensure the convergence of the solution procedure. However, the large values are not suitable because a further decline in the damping factor affects the solution significantly. Thus, the maximum value for damping is $1 \mathrm{e}-6$, as further decreases do not cause any substantial changes. 
The Modified Mohr - Coulomb and Drucker - Prager Models. Influence of Eccentricity on Hysteresis Loop and Energy Loss

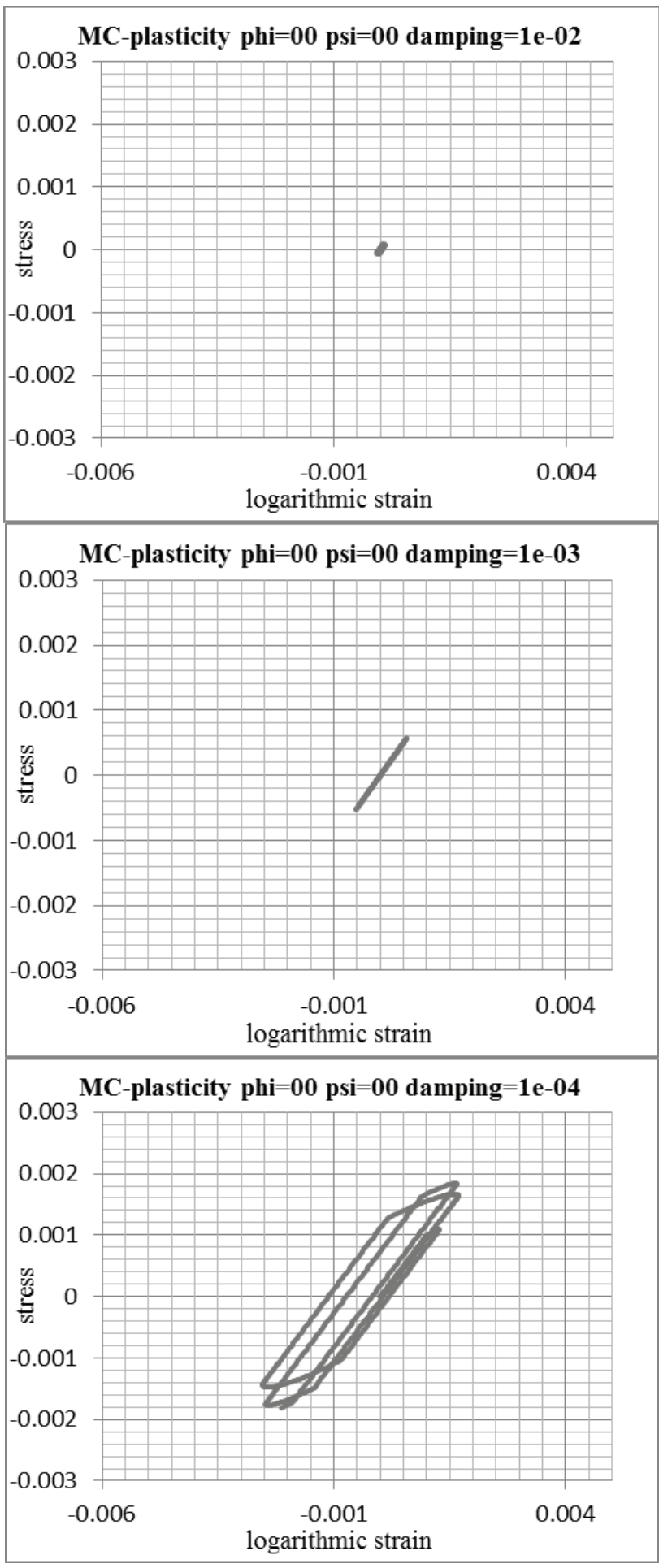

Figure 4. Stress-strain curves for asymmetric cycle loading at different values of damping.

Similar results were obtained for asymmetric loading (Figures 4 and 5). The charts in Figures 4 and 5 are plotted at $\varphi=\psi=0, c=0.001$, decc $=1$ and $m e c c=1$.
Thus, to be suitable for the problem, the value of the damping factor should not affect the character of stress-strain curves when it decreases.
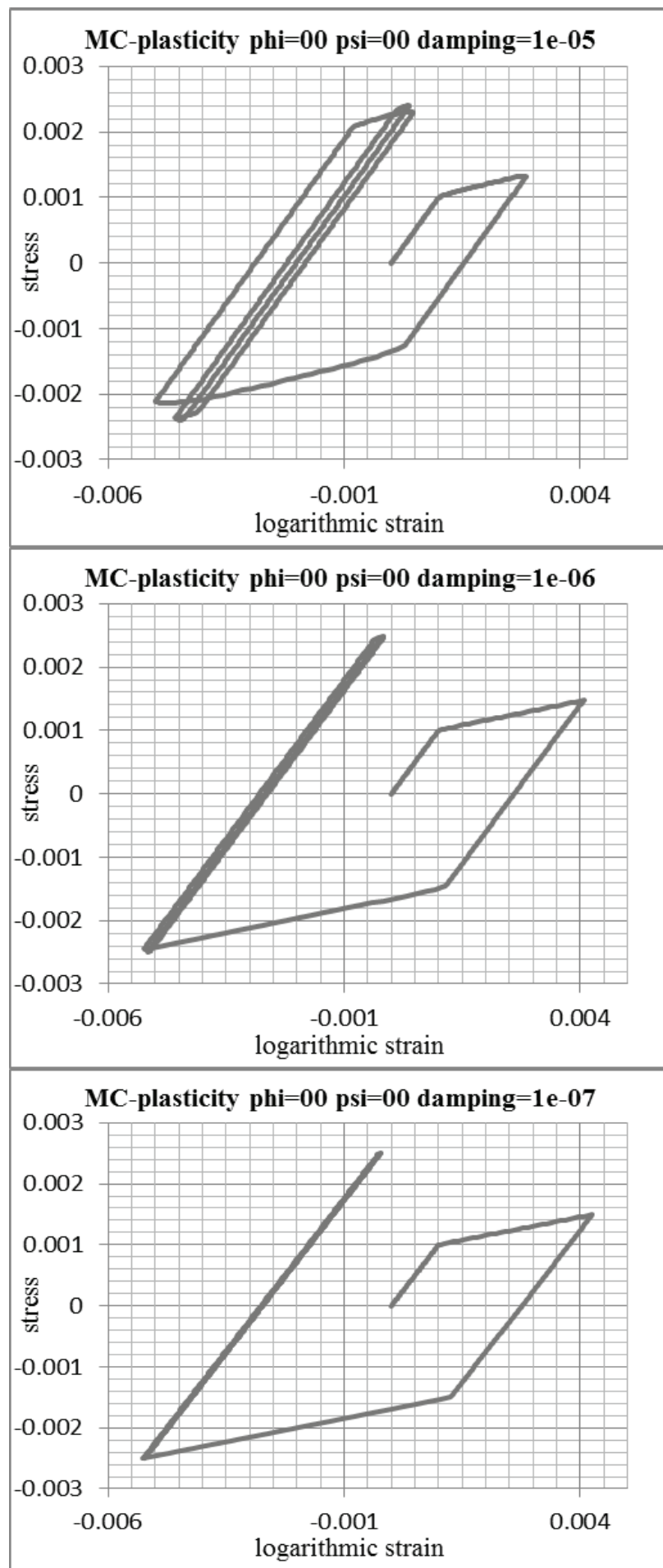

Figure 5. Stress-strain curves for asymmetric cycle loading at different values of damping. 

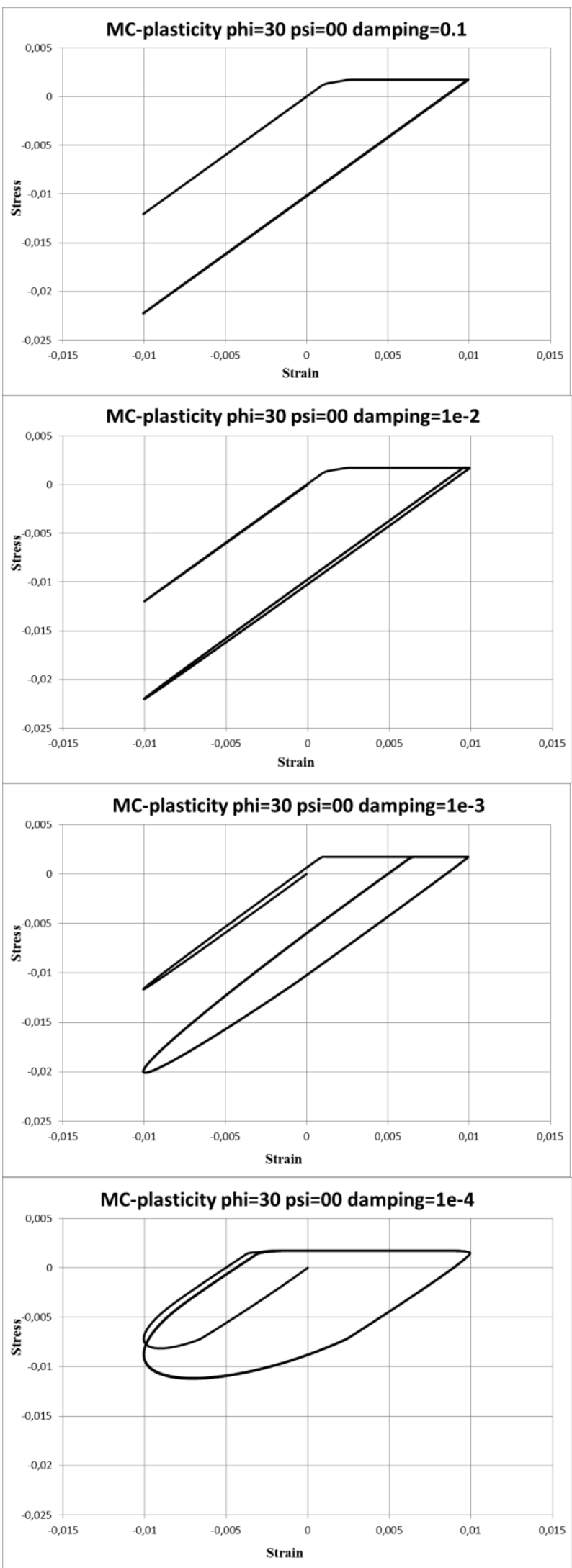

Figure 6. Stress-strain curves for MohrCoulomb model at different values of damping. b. Non-hardening plasticity. Figures 6 and 7 demonstrate the variation of the character of stress-strain curves due to variation of damping factor for Mohr-Coulomb model at fixed other parameters. The charts in Figures 6 and 7 are plotted at $\varphi=30, \psi=0, c=0.001$, decc $=0.56$, mecc $=0.005$ and $v=5 \mathrm{~Hz}$.
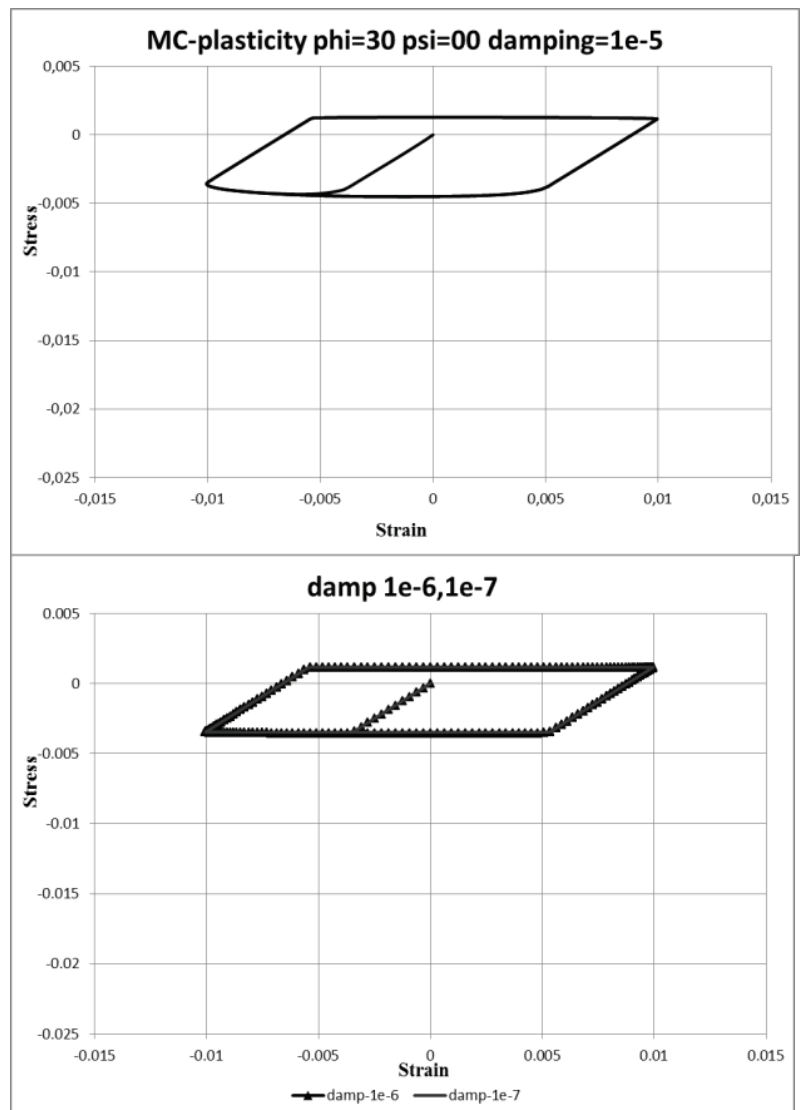

Figure 7. Stress-strain curves for Mohr Coulomb model at different values of damping.

Variation of the character of stress-strain curves due to variation of damping factor for DruckerPruger model at fixed other parameters is presented in (Figures 8 and 9). The charts in Figures 8 and 9 are plotted at $\varphi=30, \psi=0$, $c=0.001, \quad$ fecc $=0.05, \quad$ frat $=0.778$ and $v=5 \mathrm{~Hz}$. Here $\mathrm{fecc}$ is flow eccentricity and frat is flow ratio. 
The Modified Mohr - Coulomb and Drucker - Prager Models. Influence of Eccentricity on Hysteresis Loop and Energy Loss
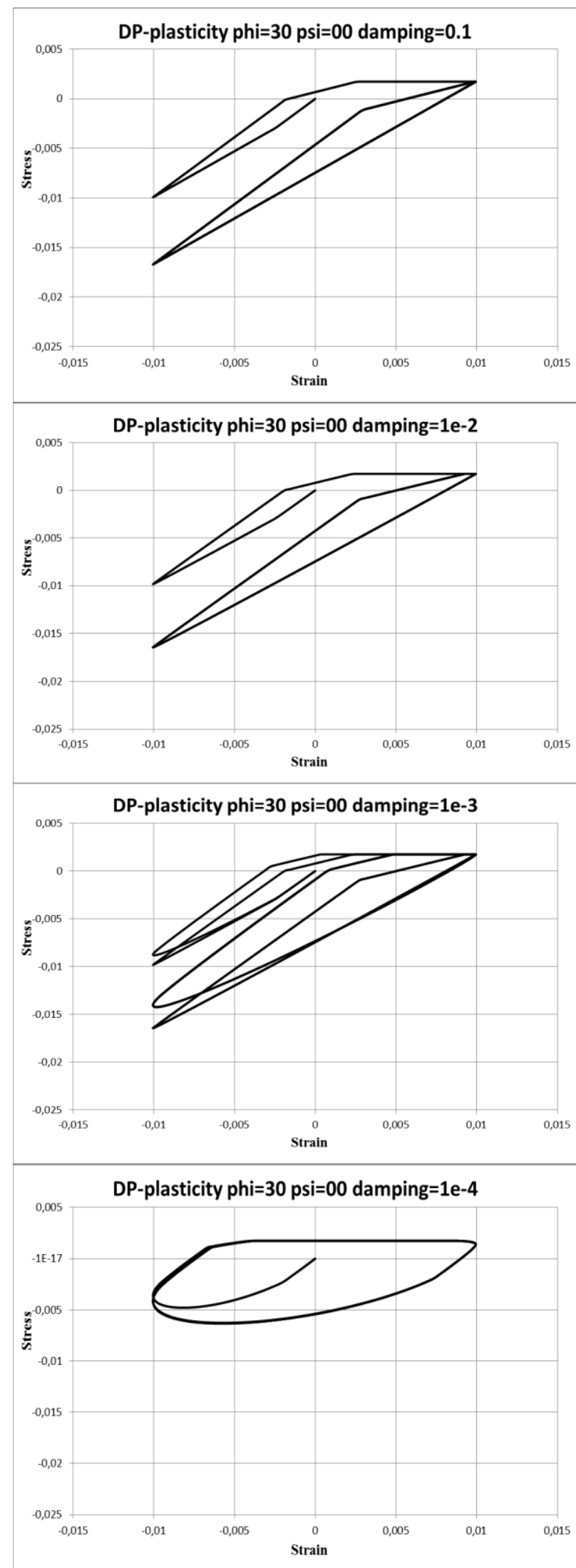

Figure 8. Stress-strain curves for DruckerPruger model at different values of damping.
The obtained results revealed that for both hardening and non -hardening types of plasticity models, the damping ratio affects the result of the solution dramatically. Any increase causes substantial changes in the character of stress- strain curves, while a damping factor equal to or less than $10^{-5}$ may ensure the convergence of the solution, meanwhile negligibly influencing the final results.

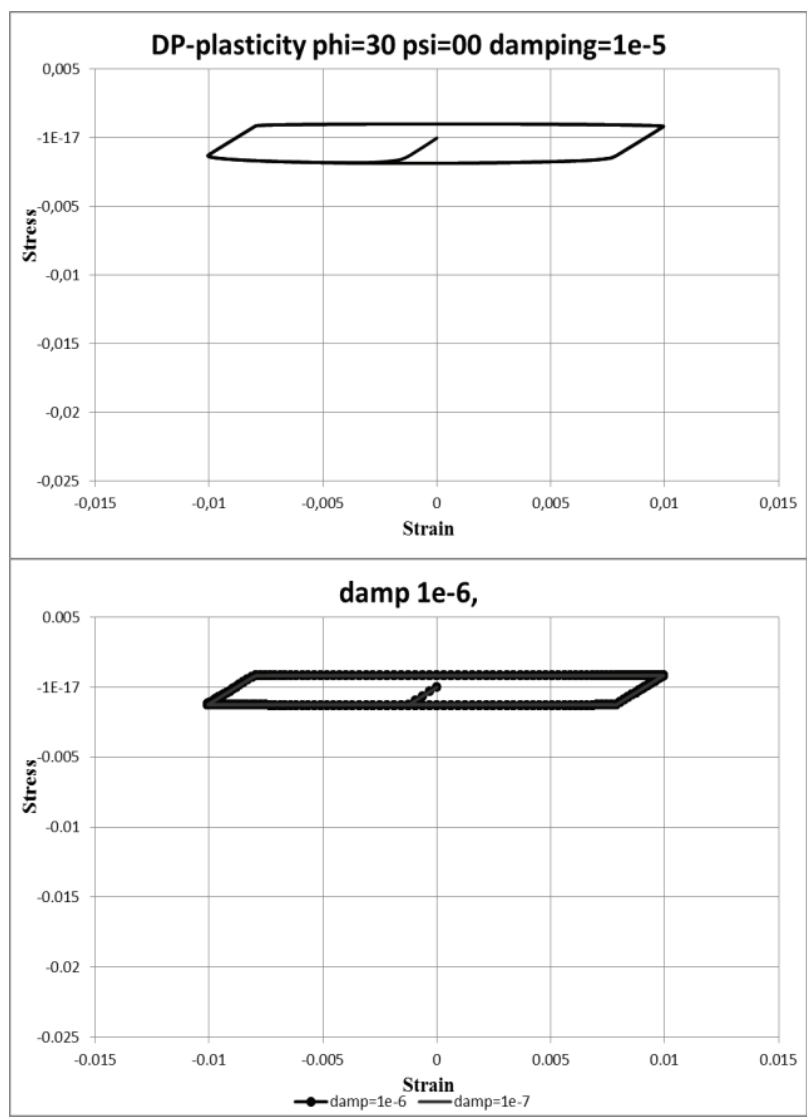

Figure 9. Stress-strain curves for DruckerPruger model at different values of damping.

2.2 The influence of eccentricities in MohrCoulomb and Drucker-Pruger models.

The influence of deviatoric and meridional eccentricities on the result can be estimated by varying the energy dissipated by plastic deformation.

Variation of the energy dissipated by plastic deformation in the Mohr-Coulmb model due to the variations of both meridional and deviatoric eccentricities is shown in (Figure 10). The 
surface in (Figure 10) is plotted at $\mathrm{t} \varphi=30$, $\psi=0, c=0.001 v=5 \mathrm{~Hz}$.

As can be seen from the chart above, the influence of deviatoric eccentricity on the energy of plastic deformation is insignificant. In addition, the variation of meridional eccentricity does not cause the change in the energy of plastic deformation, except in the case of numerical errors. These effects can be observed when the value of deviatoric eccentricity is greater than 0.75 . One possible reason behind the energy independence from the value of meridional eccentricity is that this eccentricity may be fixed in the program complex. In this case we can define it by comparing the stressstrain curve with the yield surface.

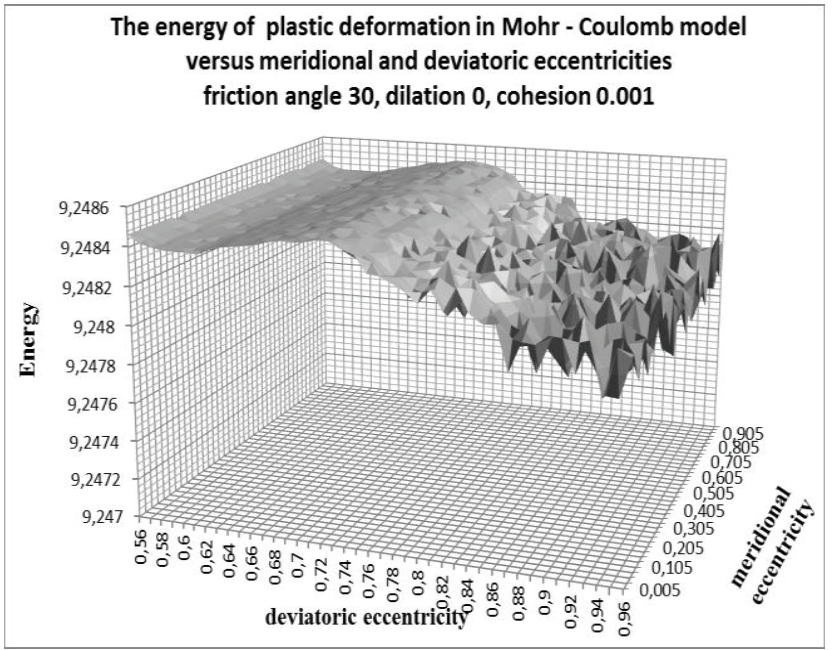

Figure 10. Variation of energy dissipated by plastic deformation due to the variations of meridional and deviatoric eccentricities.

Similarly to Mohr-Coulomb model, we can estimate the influence of the flow eccentricity and flow rate in Drucker-Pruger model. The variation of the energy dissipated by plastic deformation in Drucker-Pruger model due to the variations of flow eccentricitiy and flow rate is shown in (Figure 11). The surface in (Figure 11) is plotted at $\varphi=30, \psi=0, c=0.001 v=5 \mathrm{~Hz}$.

According to Figure 11, the variation of flow potential eccentricity does not change the energy of plastic deformation, while the flow ratio affects this quantity significantly.

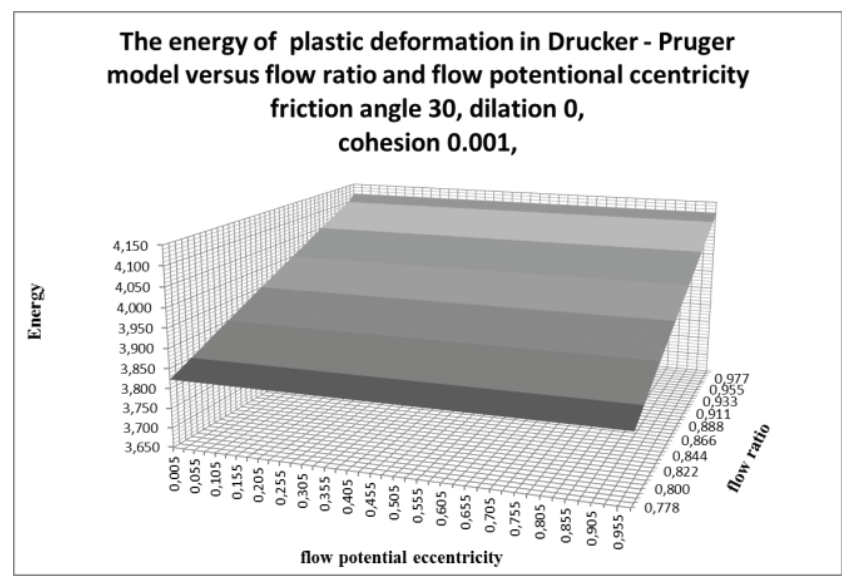

Figure 11. The variation of energy dissipated by plastic deformation due to the variations of flow eccentricity and flow rate.

In contrast to Mohr-Coulomb model there are no such deviations from the mean energy in Drucker-Pruger model. In addition, the value of flow potential eccentricity may be estimated by comparing the stress-strain curve and the yield surface.

\subsection{Yield surface.}

The Mohr-Coulomb yield surface and the loading in meridional plane are shown in (Figure 12). The curves in Figure 12 are plotted at $\varphi=30, \psi=0, c=0.001, \quad \operatorname{decc}=0.56$, $m e c c=0.005$ and $v=5 \mathrm{~Hz}$. The strain stress curve for these parameters of the model and loading is plotted in (Figure 13).

Meridional eccentricity can be solved by equation (2.3):

$$
\text { mecc }=\frac{p_{-} \text {yield }}{c} \tan \varphi,
$$

where $p_{-}$yield is the stress corresponding to the beginning of the plastic flow.

Drucker-Pruger yield surface and the loading in meridional plane are shown in (Figure 14). The curves in Figure 14 are plotted at $\varphi=30, \psi=0$, $c=0.001 v=5 \mathrm{~Hz}$. The strain stress curve for these parameters of the model and loading is plotted in (Figure 15). 
The Modified Mohr - Coulomb and Drucker - Prager Models. Influence of Eccentricity on Hysteresis Loop and Energy Loss

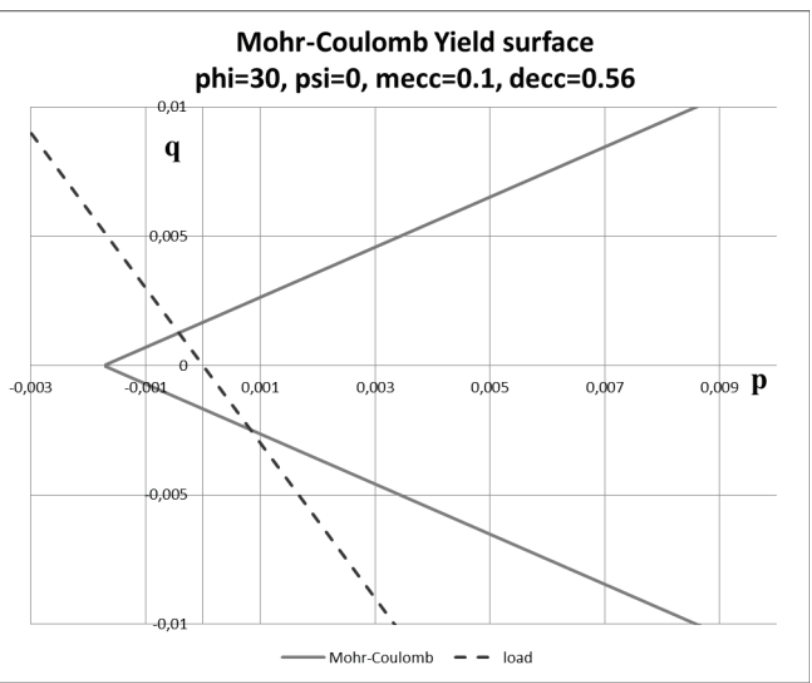

Figure 12. Yield surface for Mohr - Coulomb model.

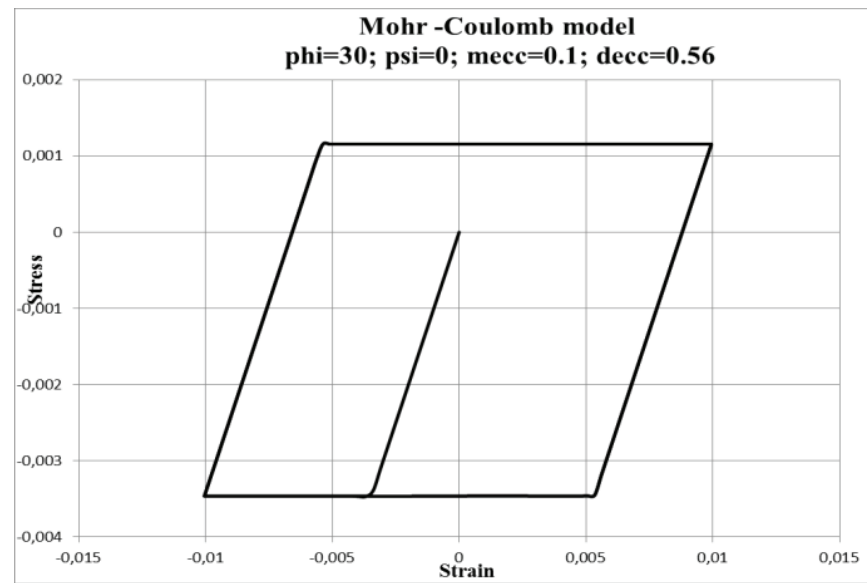

Figure 13. Stress-strain curve for MohrCoulomb model.

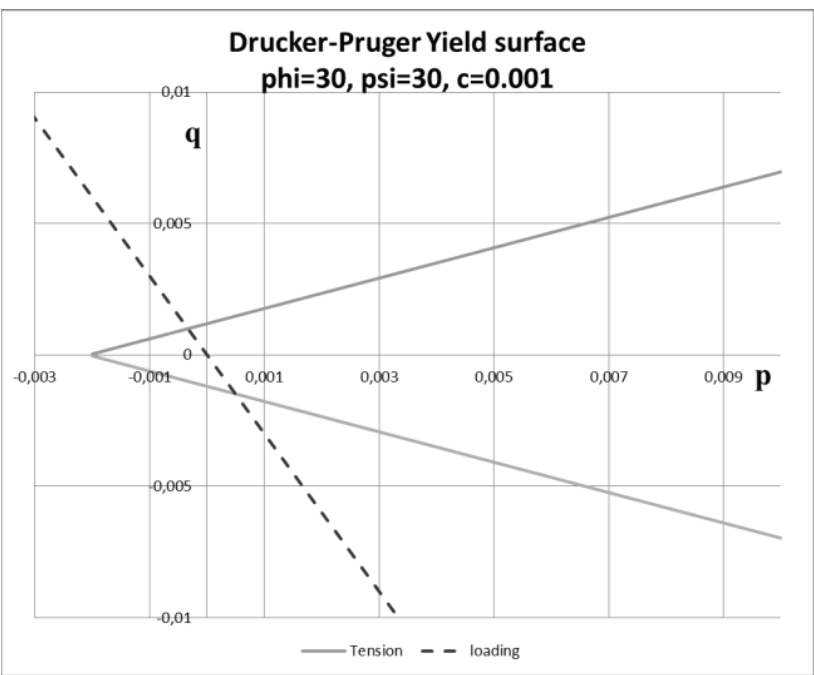

Figure 14. Yield surfaces for Drucker - Pruger model.

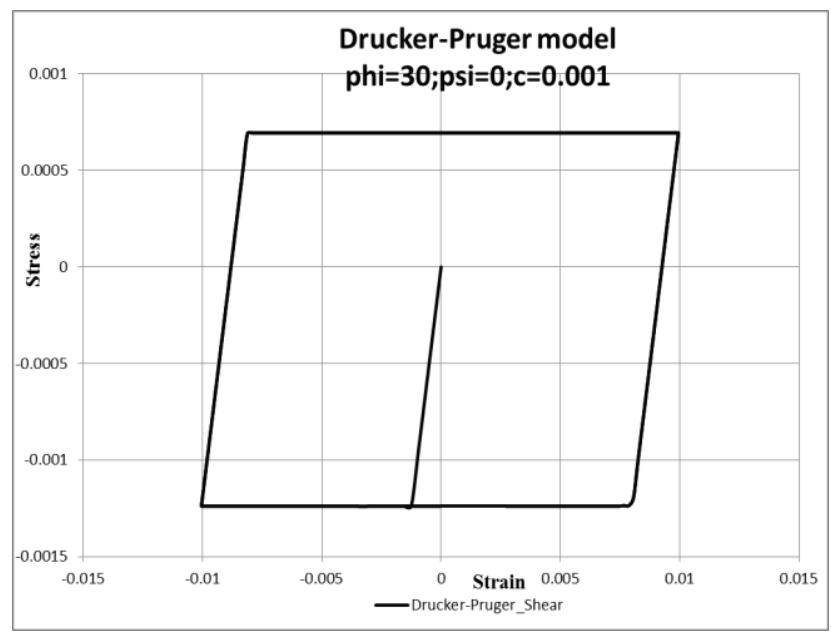

Figure 15. Stress-strain curve for DruckerPruger model.

Similarly to Mohr-Coulomb, flow eccentricity in Drucker-Pruger model can be solved by the following equation:

$$
\text { fecc }=\frac{p_{-} \text {yield }}{c} \tan \varphi .
$$

\section{CONCLUDING REMARKS}

According to the obtained results, the value of the damping factor ensures the convergence of the solution procedure (the solution was obtained for all almost values of this quantity). However, a large damping factor dramatically affects the final results. Therefore, we should decrease the damping factor to determine its optimal quantity. In case this reduction does not change the final results, the value of the damping factor is suitable.

Deviatoric eccentricity in Mohr-Coulomb model of plasticity does not affect the energy dissipated by plastic deformation significantly. Hence, it does not matter whether or not we select this value for calculations. In addition, the value of meridional eccentricity remained constant for all the calculations carried out by the authors.

In Drucker-Pruger model of plasticity, the value of flow affects the yield stress as well as the energy dissipated by plastic deformation. 
Therefore, the tuning is important for calculations and may change the final results. As with the meridional eccentricity in MohrCoulom model, the value of flow potential eccentricity remained fixed in program despite the attempts to change it. Thus, we can only estimate these values, comparing the stressstrain curves and the yield surfaces in the models.

\section{REFERENCES}

1. Menétrey Ph., William K.J. Triaxial Failure Criterion for Concrete and its Generalization. ACI Structural Journal, 1995, Vol. 92, pp. 311-318.

2. Krenk S. Characteristic state plasticity for granular materials part I: Basic Theory. International Journal of Solids and Structures, 2000, Vol. 37, pp. 6343-6360.

3. Ahadi A., Krenk S. Characteristic state plasticity for granular materials part II: model calibration and results. International Journal of Solids and Structures, 2000, Vol. 37, pp. 6361-6380.

Alexander V. Dudchenko, Ph.D. Student; Department of Strength of Materials, National Research Moscow State University of Civil Engineering; LLC "Podzemproekt"; 26, Yaroslavskoe Shosse, Moscow, 129337, Russia; tel. +7(499)183-85-59, +7(499)183-43-29; +7(926)069-88-12; e-mail: sopromat@mgsu.ru, aleks_dud@mail.ru.

Sergey V. Kuznetsov, Professor, Dr.Sc., Department of Strength of Materials, National Research Moscow State University of Civil Engineering; Institute for Problems in Mechanics, Russian Academy of Sciences; 26, Yaroslavskoe Shosse, Moscow, 129337, Russia; tel. +7(499)183-85-59, +7(499)183-43-29;

e-mail: sopromat@mgsu.ru.

Дудченко Александр Владимирович, аспирант кафедры сопротивления материалов, Национальный исследовательский Московский государственный строительный университет; ООО «Подземпроект»; 129337, Россия, г. Москва, Ярославское шоссе, д. 26; тел. +7(499)183-85-59, +7(499)183-43-29; +7(926)06988-12; e-mail: sopromat@mgsu.ru, aleks_dud@mail.ru.
Кузнецов Сергей Владимирович, профессор, доктор физико-математических наук; профессор кафедры сопротивления материалов, Национальный исследовательский Московский государственный строительный университет; Институт проблем механики Российской академии наук; 129337, Россия, г. Москва, Ярославское шоссе, д. 26; тел. +7(499)18385-59,+7(499)183-43-29; e-mail: sopromat@mgsu.ru. 